\title{
Relações entre condutividade hidráulica, transmissividade, condutância longitudinal e sólidos totais dissolvidos para o aquífero livre de Caçapava do Sul (RS), Brasil
}

Relationship among hydraulic conductivity, transmissivity, longitudinal conductance and total dissolved solids for the free aquifer of Caçapava do Sul (RS), Brazil

\section{César Augusto Moreira}

Doutor em Geociências. Professor Assistente Doutor junto ao Departamento de Geologia Aplicada (DGA), Instituto de Geociências e Ciências Exatas (IGCE), Universidade Estadual Paulista (UNESP) - Rio Claro (SP), Brasil.

\section{Mara Lia Dias Cavalheiro}

Mestranda do Programa de Pós-graduação em Geodinâmica e Geofísica do Centro de Ciências Exatas e da Terra da Universidade Federal do Rio Grande do Norte (UFRN) - Natal (RN), Brasil.

\author{
Alice Marques Pereira \\ Mestranda do Programa de Pós-graduação em Geociências da UNESP - Rio Claro (SP), Brasil.
}

\section{Felipe Caron}

Mestre em Geociências pela Universidade Federal do Rio Grande do Sul (UFRGS). Professor Assistente da Universidade Federal do Pampa (UNIPAMPA) -

Caçapava do Sul (RS), Brasil.

\section{Resumo}

A água subterrânea é um importante recurso ao abastecimento público, principalmente para comunidades periféricas em grandes cidades ou pequenos municípios, onde a instalação ou prolongamento de sistemas de distribuição são economicamente inviáveis. Estudos voltados à análise da vulnerabilidade de aquíferos são relevantes para subsídio a políticas públicas em saneamento básico e preservação ambiental. Este estudo contou com o cadastro de 23 poços rasos localizados no município de Caçapava do Sul (RS), onde foram realizadas medidas de resistividade elétrica e cargabilidade por meio de geofísica, e medidas diretas de condutividade hidráulica e sólidos totais dissolvidos. A análise estatística dos dados demonstrou diversos graus de correlação entre parâmetros, basicamente condicionados a fatores geológicos como porosidade, permeabilidade e sólidos totais dissolvidos.

Palavras-Chave: SEV; resistividade elétrica; cargabilidade; Dar Zarrouk; vulnerabilidade.

\section{Abstract}

Groundwater is an important resource for the public supply, mainly for the attendance of peripheral communities in large cities or small cities, where the installation or prolongation of distribution systems is economically unfeasible. Studies related to the vulnerability analysis in aquifers are important for subsiding public policies in basic sanitation and environmental preservation. This study was supported by the cadaster of 23 shallow wells localized in Caçapava do Sul (RS). Measurements of electric resistivity and chargeability were performed by geophysical methods, direct measures of hydraulic conductivity and total dissolved solids. The data statistics analysis demonstrated several degrees among parameters, conditioned to geological factors as porosity, permeability and total dissolved solids.

Keywords: VES; electrical resistivity; chargeability; Dar Zarrouk; vulnerability. 


\section{Introdução}

A problemática do saneamento básico é um desafio enfrentado por praticamente todos os países em desenvolvimento e basicamente consiste num conjunto de procedimentos que visam proporcionar condições mínimas de higiene e saúde para a população (BRASIL, 2007).

Tais procedimentos podem ser resumidos em tratamento e distribuição de água potável, canalização e tratamento de esgoto, limpeza pública de ruas e avenidas, e coleta e tratamento de resíduos orgânicos e passíveis de reciclagem ou reaproveitamento. Os objetivos do saneamento básico são: controle e prevenção de doenças e melhoria da qualidade de vida da população, sob condições de mínimo impacto ambiental (SUGUIO, 2008).

O abastecimento de água é uma questão essencial para a população, pois sua ausência ou fornecimento inadequado resulta em grande risco à saúde pública. Em 2000, o país possuía 5.561 municípios, dos quais $97,9 \%$ contavam com serviços públicos de abastecimento de água. Entretanto, somente 46\% dos domicílios situados em cidades com até 20.000 habitantes contavam com este instrumento de saneamento (IBGE, 2000).

Aproximadamente $75 \%$ dos municípios com até 20.000 habitantes do Rio Grande do Sul são abastecidos por fonte subterrânea explorada por órgãos públicos ou privados, com distribuição, em grande parte, limitada às áreas urbanas (IBGE, 2000).

A captação de água em aquíferos rasos é um procedimento bastante comum para atendimento a demandas de abastecimento de população de baixa renda e da zona rural, em áreas desprovidas de sistemas públicos ou particulares de abastecimento de água. Poços rasos representam sistemas de baixo custo e de construção simplificada, frequentemente escavados por meio de ferramentas manuais e limitados a algumas dezenas de metros de profundidade (GONÇALVES e GIAMPÁ, 2006).

Estudos voltados ao entendimento de sistemas aquíferos, principalmente quanto aos fatores relativos à recarga, armazenamento, transmissividade e definição de áreas favoráveis à perfuração de poços produtores ou preservação, são fundamentais para a disponibilidade deste importante recurso para as futuras gerações (HANSEN et al., 2010).

Estudos de vulnerabilidade são particularmente importantes para aquíferos livres devido ao elevado potencial de aporte de contaminações proveniente de atividades de agricultura, pecuária ou esgotamento sanitário para o caso de zonas rurais, além de contaminantes oriundos de atividades industriais e comerciais.

Os componentes que determinam a vulnerabilidade de aquíferos livres são resultantes de uma combinação de fatores, que podem ser resumidos em: profundidade do nível freático, espessura seca, transicional e saturada dos horizontes e características litológicas e hidráulicas do conjunto de materiais que constituem o aquífero. Trabalhos neste sentido são, em grande parte, baseados em dados diretos obtidos em poços de abastecimento, algo que muitas vezes pode dificultar estudos de vulnerabilidade em áreas desprovidas ou com pequeno número de poços, diante da baixa representatividade geológica dos dados em tratamentos estatísticos (GONÇALVES e GIAMPÁ, 2006; HANSEN et al., 2010).

A geofísica é uma ciência baseada no estudo de propriedades físicas intrínsecas aos materiais geológicos, como densidade, radioatividade e magnetização, de forma indireta e não invasiva. A partir das diversas técnicas e métodos existentes, o seu principal objetivo é a busca de contrastes em propriedades físicas adquiridas por meio de instrumental de aquisição aéreo, terrestre, de subsuperfície ou subaquático.

Dentre os métodos utilizados encontram-se os Elétricos e Eletromagnéticos, ferramentas de destaque em estudos hidrogeológicos por conta da ampla gama de variação do parâmetro resistividade elétrica em solos e rochas. O parâmetro cargabilidade, medido por meio do método de polarização induzida, apresenta potencial aplicação em estudos hidrogeológicos devido à existência de fenômenos de polarização gerados em presença de argilominerais no solo ou sais dissolvidos.

A possibilidade de medidas da variação de parâmetros físicos de forma indireta e multipontual, influenciados por condicionantes hidrogeológicos como a variabilidade no tipo de fluído intraporo (ar, água), composição química do fluído (conteúdo de sais dissolvidos), constituintes minerais (quartzo, minerais metálicos), granulometria predominante (argila, silte, areia), dentre outros, permite o desenvolvimento de estudos de relação com parâmetros hidráulicos diretos (SAINATO et al., 2006; OKORO et al., 2010; PEINADO-GUEVARA et al., 2010; SALEM, 2001; SHEVNIN et al., 2006; SOUPIOS et al., 2007).

Os trabalhos de Braga (2008), Braga et al. (2006), Melo et al. (2006) e Souza e Verma (2006) adotam o parâmetro condutância longitudinal em estudos de vulnerabilidade de aquíferos, com base em sua relação com a fração argila eventualmente presente nestes ambientes.

Este trabalho apresenta os resultados de estudo hidrogeológico desenvolvido por meio de medidas diretas de condutividade hidráulica e sólidos totais dissolvidos em poços rasos, indiretas de resistividade elétrica e cargabilidade por meio de geofísica, além de estimativas de transmissividade e condutância longitudinal. O objetivo é avaliar eventuais relações estatísticas entre parâmetros, verificar a aplicabilidade do parâmetro resistividade elétrica em investigações acerca da produtividade de aquíferos rasos, além de conferir as potencialidades do uso de medidas de cargabilidade em estudos hidrogeológicos e fatores que condicionam o fenômeno de polarização induzida num aquífero livre, como sais dissolvidos na água e argilosidade do material. 


\section{Localização da área}

A área de estudos está localizada em Caçapava do Sul, município da região Centro-Sul do Rio Grande do Sul (Figura 1). Esta localidade dista cerca de $260 \mathrm{~km}$ de Porto Alegre e pode ser acessada por meio da rodovia BR-290. O local tem sua economia baseada na mineração de calcários, comércio, pecuária e agricultura, e sua população totaliza cerca de 32 mil pessoas

Parte substancial dos munícipes reside da zona rural, praticamente desprovida de elementos de saneamento básico, como distribuição de água tratada e rede de coleta de esgoto. Neste caso, o abastecimento de água para consumo humano provém de poços rasos, para captação em aquífero livre situado no solo de alteração do batólito granítico regional.

O descarte de resíduos líquidos domiciliares é realizado em fossas negras ou diretamente em pequenos cursos d'água. Em contrapartida, a área urbana possui água tratada por rede pública de abastecimento, além de rede de coleta de esgoto, embora o efluente seja totalmente lançado nos rios locais, sem qualquer tratamento

Quanto ao contexto geológico, a área de estudos faz parte da Suíte Granítica Caçapava do Sul, classificada como granitoides sintranscorrentes contidos no Domínio Ocidental do Escudo Sul-Rio-Grandense, representados por corpos plutônicos intrusivos nas unidades metamórficas do Domínio Ocidental, com foliação milonítica relacionada a eventos transcorrentes (CPRM, 2000)

Esta suíte compreende dois corpos graníticos intrusivos na associação metassedimentar do Complexo Metamórfico Vacacaí. As relações de contato entre rochas graníticas e encaixantes são marcadas por apófises, geralmente concordantes ou de baixo ângulo com a foliação principal dos metamorfitos. A foliação milonítica dos granitoides é, de maneira geral, concordante com a foliação principal da sequência metamórfica.

É dominantemente constituída por monzogranitos e sienogranitos, com participação subordinada de rochas de composição granodiorítica a tonalítica presentes na borda Oeste do corpo principal, subdivididas em três fácies principais: biotita granitos, leucogranitos e granitos transicionais (CPRM, 2000).

A constituição mineralógica principal está representada por proporções variadas de quartzo, feldspato alcalino e plagioclásio, com biotita presente nas diversas fácies como mineral varietal e hornblenda identificada apenas nos tipos tonalíticos. Os minerais acessórios mais comuns estão representados por zircão, allanita, apatita e minerais opacos, além de titanita e rutilo. Clorita, epidoto, muscovita, carbonato e opacos secundários constituem a mineralogia resultante do metamorfismo associado à fase de deformação transcorrente (CPRM, 2000).
Os solos da suíte granítica são classificados em duas unidades: podzólico vermelho-amarelo eutrófico e podzólico vermelho-amarelo distrófico (IBGE, 2002).

O perfil de alteração baseado em descrições de campo é constituído por solo argiloso, sotoposto por saprolito com fragmentos de tamanhos variáveis de granito parcialmente alterado, sob rocha granítica inalterada. Estas constatações apontam para um perfil de alteração in situ, ausente de quaisquer evidências de solo transportado.

Os pontos selecionados para estudo neste trabalho estão posicionados, em sua maioria, nas cotas mais elevadas da região estudada, caracterizada por um relevo extenso e pouco ondulado, com perfil de alteração espesso e desenvolvido, susceptível a pressões atmosféricas e infiltração de águas meteóricas que percolam o solo permeável até o contato solo/rocha, que, por sua vez, define uma superfície altamente impermeável, exceto por fluxo em fraturas em pontos localizados

\section{Materiais e métodos}

O método da Eletrorresistividade é baseado na geração de um campo elétrico em subsuperfície por injeção de corrente elétrica (I) por meio de um dispositivo, representado por hastes metálicas, denominado circuito transmissor (KEAREY et al., 2002). O potencial elétrico $(\Delta \mathrm{V})$ produzido pela passagem deste campo é captado por meio de um circuito receptor, que também pode ser representado por hastes metálicas ou eletrodos impolarizáveis. Os circuitos de transmissão e recepção são posicionados em superfície, segundo um arranjo geométrico preestabelecido.

A aplicação da Lei de $\mathrm{Ohm}$, onde $\Delta \mathrm{V}$ representa a variação de voltagem e I a corrente elétrica, que considera o espaçamento entre os eletrodos, representado por um fator denominado K, permite medidas do parâmetro resistividade aparente ( $\rho$ a) para vários níveis de profundidade (Equação 1):

$\rho \mathrm{a}=\mathrm{K} \frac{\Delta \mathrm{V}}{\mathrm{I}} \Omega \cdot \mathrm{m}$

O método de Polarização Induzida (IP) é baseado num fenômeno de estimulação de corrente elétrica, observado após o retardo ou atraso de um sinal de voltagem em materiais de subsuperfície (SUMNER, 1976). Este método também consiste no emprego de um dispositivo eletródico de transmissão para injeção de corrente elétrica pulsante e periódica em subsuperfície, cuja resposta é obtida por meio de um circuito receptor constituído de eletrodos impolarizáveis.

A curva de decaimento transiente representa retorno ao estado original de repouso consequente do distúrbio devido à aplicação de uma corrente elétrica. Durante o tempo de aplicação desta corrente, uma fração da energia é armazenada em solos e rochas, resultante 
de variações da mobilidade de íons em meio poroso/fraturado ou da variação entre condutividade iônica e eletrônica em presença de minerais metálicos (REYNOLDS, 1997; TELFORD et al., 2004).

Os parâmetros de medidas de polarização induzida no domínio do tempo são determinados pela característica da forma da curva de potencial transiente, que pode ser a porcentagem de polarização induzida, integral tempo-transiente e cargabilidade (TELFORD et al., 2004). A cargabilidade é definida pelo potencial transiente $\left(\mathrm{V}_{\mathrm{t}}\right)$ variável entre dois pontos da curva de decaimento transiente, normalizada pelo potencial primário $\left(\mathrm{V}_{c}\right)$, definido pela Equação 2:

$\mathrm{M}=\frac{1}{\mathrm{~V}_{\mathrm{c}}} \int_{\mathrm{t} 2}^{\mathrm{t} 1} \mathrm{~V}_{\mathrm{t}} \mathrm{dt} \quad \mathrm{mV} / \mathrm{V}$

Segundo Fetter (1994), transmissividade (T) é um parâmetro hidráulico diretamente relacionado à condutividade hidráulica $(K)$ e espessura da camada (b), conforme a Equação 3.

$\mathrm{T}=\mathrm{Kb} \quad \mathrm{cm}^{2} . \mathrm{S}$

Dentre os parâmetros Dar Zarrouk, a condutância longitudinal (Si) permite uma estimativa da vulnerabilidade de aquíferos devido à sua relação com a argilosidade de camadas sedimentares (BRAGA et al., 2006), numa relação de espessura (hi) e resistividade da camada ( $\rho$ i) calculado pela Equação 4.

$\mathrm{Si}=\frac{h i}{\rho \mathrm{i}}$ Siemens
O procedimento adotado neste trabalho consistiu inicialmente na localização de 23 poços rasos no município de Caçapava do Sul (RS), por meio de diversas visitas de campo, solicitação de acesso à área $e$ georreferenciamento dos pontos (Figura 1).

A etapa seguinte contemplou a obtenção de dados geofísicos, geológicos e hidrogeológicos para cada poço selecionado. A aquisição de dados geofísicos envolveu a aplicação dos métodos da eletrorresistividade e da polarização induzida, por meio da técnica de sondagem elétrica vertical em arranjo Schlumberger, com leitura dos parâmetros físicos resistividade elétrica (em $\Omega \mathrm{m}$ ) e cargabilidade (em $\mathrm{mV} / \mathrm{V})$.

Foi utilizado resistivímetro Syscal Pro, constituído por uma unidade transmissora e uma receptora, configuradas para realizar medidas simultâneas de resistividade e cargabilidade no domínio do tempo. Após alguns testes preliminares de campo, foram estabelecidos os seguintes parâmetros de aquisição: $200 \mathrm{~V}$ de tensão, tempo de leitura de $1.000 \mathrm{~ms}$, janela única de $80 \mathrm{~ms}$

O ponto central de cada ensaio geofísico foi posicionado à montante do poço segundo a topografia do local, com abertura do arranjo em direção perpendicular ao declive topográfico. O arranjo consistiu na abertura máxima de $25 \mathrm{~m}$ para eletrodos de corrente para cada lado a partir do centro e movimentação para leitura a cada metro, com eletrodos de potencial posicionados a 0,3 m e 2,0 m também a partir do centro do arranjo.

Foram utilizados eletrodos não polarizáveis à base de uma solução de sulfato de cobre supersaturada $\left(\mathrm{Cu}-\mathrm{CuSO}_{4}\right)$ para as medidas geofísicas, caracterizados por um fio de cobre em seu interior e base porosa, que permite o trânsito da solução e percolação no
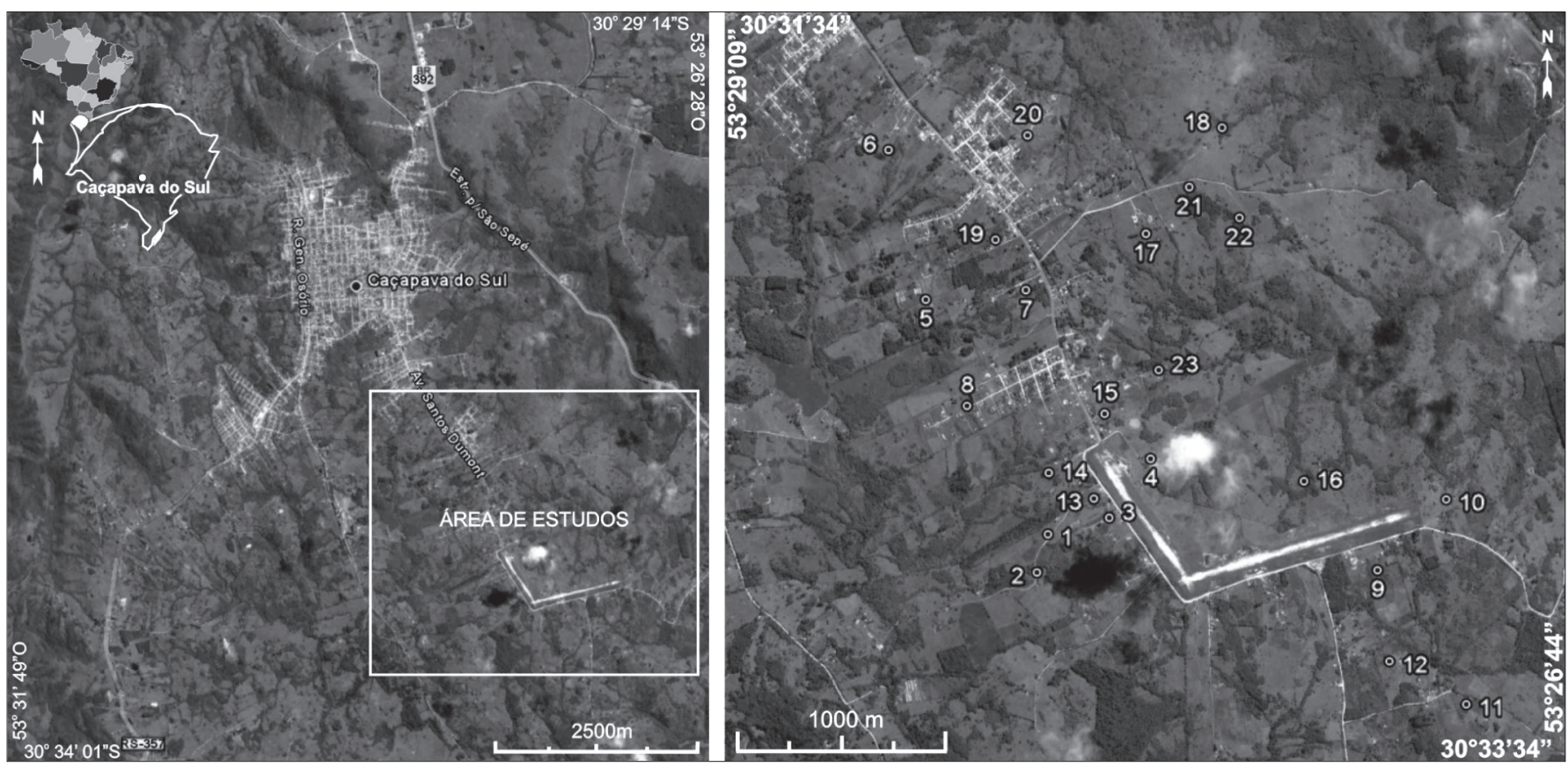

Figura 1 - Área de estudos, com detalhe para a localização dos poços verificados. 
solo. Este procedimento reduz a resistência de contato e minimiza a geração de correntes parasíticas geradas pelo uso de eletrodos metálicos para leituras.

Realizaram-se medidas de cota do nível freático e ensaios de condutividade hidráulica concomitantes à aquisição dos dados geofísicos.

O ensaio de condutividade hidráulica foi baseado no princípio de vasos comunicantes, com retirada de água por gravidade com auxílio de mangueira. Estabelecido o fluxo hidráulico no sistema, houve o monitoramento constante de rebaixamento do nível freático e regulagem do fluxo na extremidade da mangueira, até o estabelecimento de fluxo hidráulico com nível freático estacionário. Na sequência, realizaram-se três medidas do tempo de preenchimento de um recipiente com capacidade para 20 L, com adoção do valor médio de condutividade hidráulica.

Na sequência ao ensaio de condutividade hidráulica, coletaram-se amostras de água em cada poço estudado, para medidas de sólidos totais dissolvidos, por meio do equipamento portátil PH-1500.

Os dados geofísicos foram processados no programa IX1D. Fundamentado em critérios pré-determinados verificados em campo, o processamento das sondagens foi baseado em um modelo de três camadas, de forma concomitante para os parâmetros resistividade elétrica e cargabilidade. Foram obtidos níveis geoelétricos e seus respectivos valores de resistividade e cargabilidade, além da espessura de cada camada e o erro médio quadrático (RMS) de ajuste entre a curva de campo e curva teórica do programa.

\section{Apresentação e discussão dos resultados}

As descrições de campo referentes ao perfil de alteração revelam a existência de aquífero livre, caracterizado por solo seco, sucedido por solo saturado e rocha inalterada. A transição entre solo seco e solo saturado é gradual no contexto descrito na área.

O processamento das sondagens elétricas de forma conjunta produziu resultados satisfatórios, com erro médio quadrático (RMS) baixo e variável entre 2,55 e 8,90\%. Uma análise preliminar dos valores obtidos por nível geoelétrico nas diversas curvas indica ampla variação, para os parâmetros físicos investigados:

- $\quad 1^{\circ}$ nível geoelétrico: valores variáveis entre 579,8 e 10.936,0

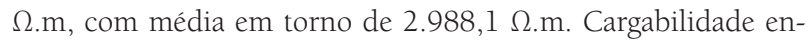
tre 1,27 a $12,31 \mathrm{mV} / \mathrm{V}$, com média em torno de 5,27 mV/N. Corresponde ao horizonte de solo seco.

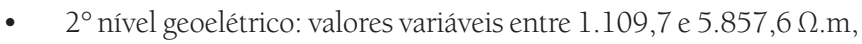
com média em torno de 4.495,1 $\Omega$.m. Cargabilidade entre 1,22 e 23,9 mV/N, com média em torno de 7,43 mV/V. Corresponde ao horizonte de zona saturada ou nível da camada aquífera.

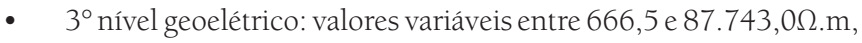
com média em torno de 12.305,9 $\Omega$.m. Cargabilidade entre
1,84 m e 42,78 mV/V, com média em torno de 16,25 mV/N. Corresponde ao horizonte de sustentação do aquífero, representado por granito.

Os parâmetros referentes ao segundo nível geoelétrico ou camada aquífera foram tabelados e resultaram em diagramas de dispersão bidimensionais. Também foram tabelados os dados de condutividade hidráulica e sólidos totais dissolvidos diretamente medidos em poços, a transmissividade calculada a partir da espessura da camada aquífera estimada pelas sondagens elétricas, além da condutância longitudinal, determinada a partir dos dados de processamento das sondagens elétricas.

Esta forma de apresentação foi adotada com o objetivo de tornar visíveis eventuais correlações entre os parâmetros envolvidos, bem como seus respectivos graus de relação, a partir do ajuste de linhas de tendência e coeficientes de determinação.

Foram constituídas as seguintes relações:

- Resistividade versus condutividade hidráulica;

- Cargabilidade versus condutividade hidráulica;

- Espessura da camada saturada versus resistividade;

- Espessura da camada saturada versus cargabilidade;

- Transmissividade versus resistividade;

- Transmissividade versus cargabilidade;

- Sólidos totais dissolvidos versus cargabilidade;

- Cargabilidade versus condutância longitudinal.

Para cada gráfico foi atribuída uma linha de tendência, equação de reta e coeficiente de determinação $\mathrm{R}^{2}$. Este coeficiente mede a proporção da variação do parâmetro do eixo y, que pode ser explicada pela variação do eixo x, entre 0 a 1 .

Os pontos representados nos gráficos por losangos correspondem aos utilizados para ajuste da linha de tendência, enquanto os círculos foram desconsiderados neste ajuste, com base no critério de exclusão de pontos com desvio padrão superior ao dobro dos valores de ajuste das respectivas linhas de tendência.

No gráfico de condutividade hidráulica versus resistividade, todos os valores apresentaram agrupamento que permitiu ajuste linear e coeficiente de determinação $R^{2}=0,9018$. Neste caso, os parâmetros relacionados demonstram relação de proporcionalidade inversa, ou seja, o aumento da resistividade é concomitante ao decréscimo da condutividade hidráulica (Figura 2).

A relação inversa de aumento da resistividade e queda da condutividade hidráulica corrobora a hipótese de aumento nos teores de argilominerais e consequente redução na quantidade relativa de água intraporo. A resistividade elétrica é diretamente condicionada ao grau de saturação do solo e, conforme demonstram os resultados, proporcional à porosidade efetiva e transmissividade no âmbito de um aquífero poroso. Portanto, a 
quantidade de água disponível para extração é proporcional à resistividade elétrica do horizonte saturado.

No gráfico sobre condutividade hidráulica versus cargabilidade, foi realizado um ajuste polinomial de grau 2, com coeficiente de determinação $R^{2}=0,7285$. A linha de tendência apresenta ascendência constante entre os valores plotados até 0,0222 L/s, quando ocorre inflexão da linha e queda nos valores de cargabilidade, com aumento da condutividade hidráulica. Esta inflexão coincide com um valor de cargabilidade de 9,9 mV/V (Figura 2).

A relação entre cargabilidade e condutividade hidráulica pode ser avaliada em duas situações. $\mathrm{O}$ aumento constante da cargabilidade até 0,0222 L/s pode estar associado ao incremento do fluxo, quantidade de íons e argilominerais solúveis, além da interconectividade dos poros. Tais condições são propícias à ocorrência do fenômeno de polarização eletrolítica, pois, embora haja condições crescentes para fluxo de fluídos, eventuais zonas de estrangulamento ou de menor porosidade condicionam a movimentação lenta de íons e argilominerais dissolvidos (KELLER e FRISCHKNECHT, 1966).
Sob a ação de corrente elétrica gerada pelo instrumental geofísico, estas interfaces apresentam o comportamento de baterias, pelo acúmulo de cargas elétricas opostas em ambos os lados. Os elementos opostos tendem a retornar as posições iniciais após o corte da corrente elétrica, ao passo que liberam potencial elétrico armazenado, cujo somatório resulta no potencial elétrico medido e relativizado à voltagem injetada no solo.

A magnitude de voltagem induzida é proporcional à quantidade de zonas de estrangulamento concomitantes à existência de poros interconectados e preenchidos por solução. Contudo, a cargabilidade acaba por decrescer a partir de determinado ponto, em que a porosidade e permeabilidade aumentam e a quantidade de zonas de estrangulamento diminui, conforme sugere a relação cargabilidade versus condutividade hidráulica para áreas com produção acima de 0,0222 L/s.

Nas relações espessura da camada saturada versus resistividade e espessura da camada saturada versus cargabilidade não foi possível o ajuste de linha de tendência, devido à ampla dispersão dos

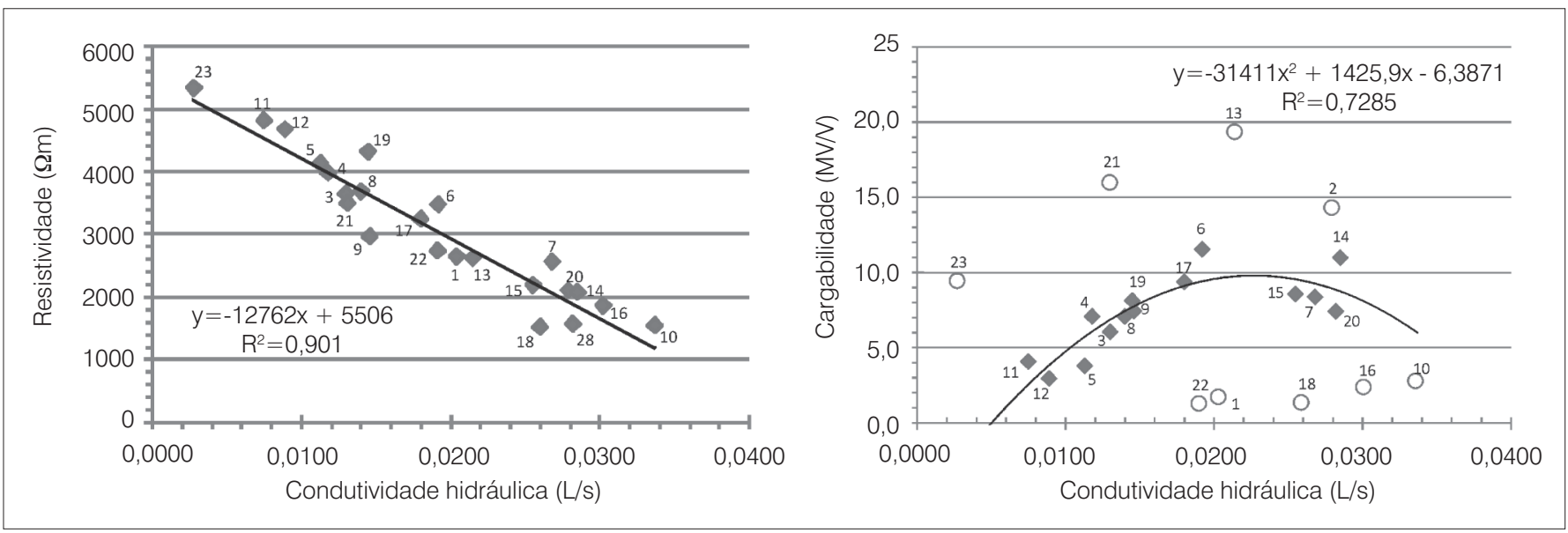

Figura 2 - Condutividade hidráulica versus resistividade (esquerda) e condutividade hidráulica versus cargabilidade (direita), com linha de tendência, equação da reta e coeficiente de determinação $\mathrm{R}^{2}$ e numeração dos símbolos referentes aos poços apresentados em mapa.

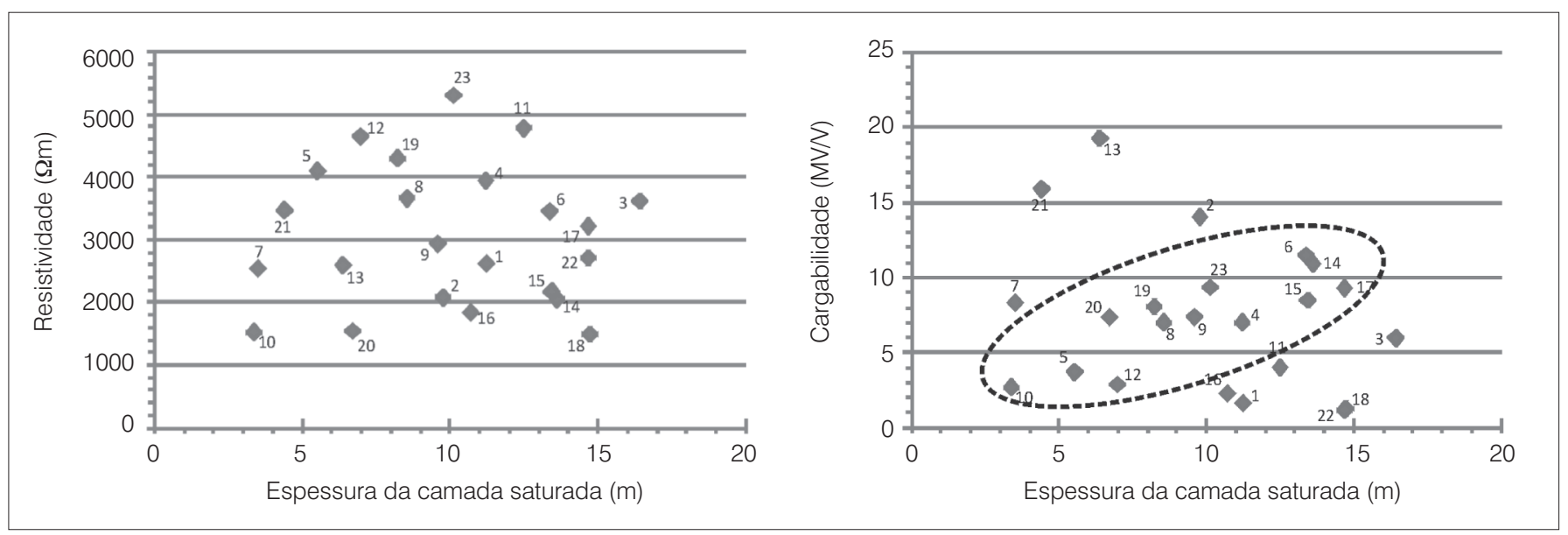

Figura 3 - Espessura da camada saturada versus resistividade (esquerda) e espessura da camada saturada versus cargabilidade (direita), com realce para área de agrupamento de pontos para o caso da relação de cargabilidade. A numeração dos símbolos segue os poços apresentados em mapa. 
dados (Figura 3). Embora seja um fator não correlacionável com medidas de resistividade ou cargabilidade para a zona saturada, o aumento da espessura desta camada possibilita, teoricamente, a queda da resistividade.

Para o caso da cargabilidade, há um agrupamento de pontos realçados no gráfico, o que indica tendência de relação direta dos parâmetros, ou seja, aumento da espessura da camada saturada concomitante ao da cargabilidade. Este indicativo corrobora a hipótese da necessidade de zonas de estrangulamento ao fluxo de água e íons em solução, como pressuposto para a geração do fenômeno de polarização eletrolítica, pois o incremento da espessura saturada colabora para o das condições de polarização (Figura 3).

No gráfico transmissividade versus resistividade foi realizado um ajuste linear com coeficiente de determinação $R^{2}=0,636$. A linha de tendência apresenta uma relação inversa, com aumento da transmissividade concomitante à queda de resistividade (Figura 4).
Embora a espessura da camada saturada não seja diretamente relacionável, a transmissividade, que resulta da multiplicação da espessura pela condutividade hidráulica, revelou razoável grau de relação com a resistividade. Este resultado possivelmente deriva do elevado grau de relação dos parâmetros condutividade hidráulica versus resistividade.

No gráfico transmissividade versus cargabilidade foi realizado um ajuste linear com coeficiente de determinação $R^{2}=0,5289$ (Figura 4). A linha de tendência apresenta ascendência suave numa relação direta, com aumento da transmissividade proporcional ao da cargabilidade.

No gráfico cargabilidade versus sólidos totais dissolvidos foi realizado ajuste linear com coeficiente de determinação $\mathrm{R}^{2}=0,3734$. A linha de tendência apresenta relação direta entre parâmetros, com aumento da cargabilidade concomitante ao do teor de sólidos totais dissolvidos na água, embora em uma situação de baixo coeficiente de determinação (Figura 5).

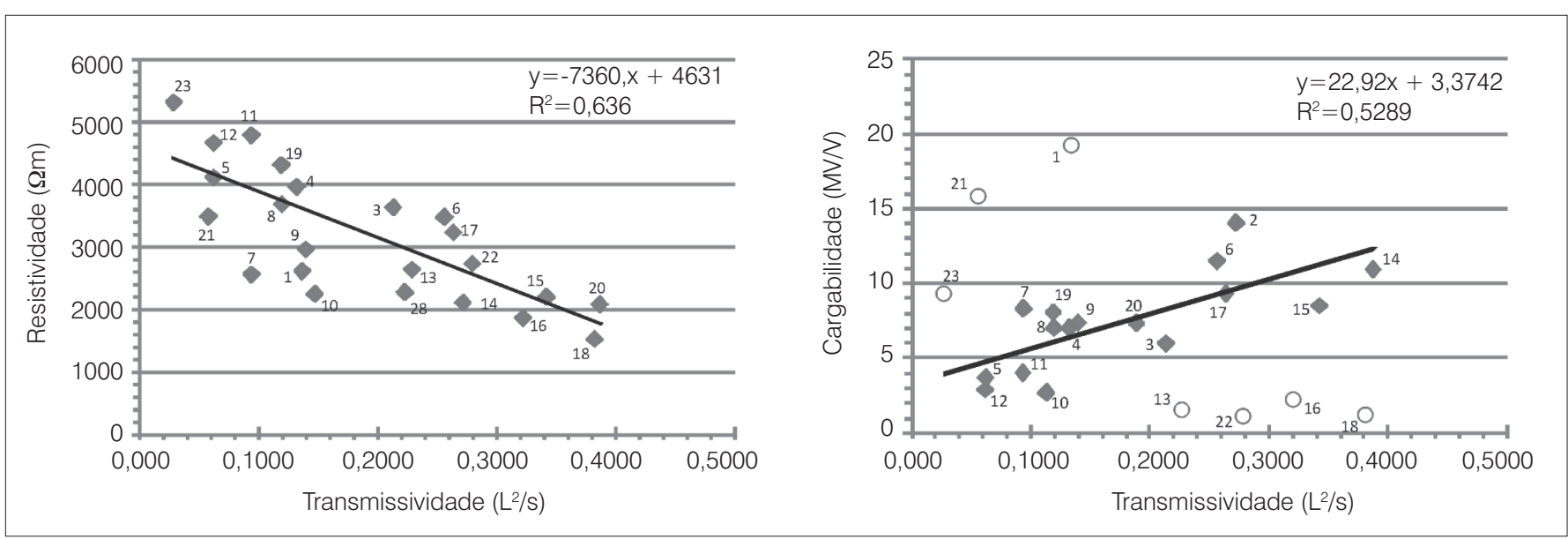

Figura 4 - Transmissividade versus resistividade (esquerda) e transmissividade versus cargabilidade (direita), com linha de tendência, equação da reta, coeficiente de determinação $\mathrm{R}^{2}$ e numeração dos símbolos referentes aos poços apresentados em mapa.
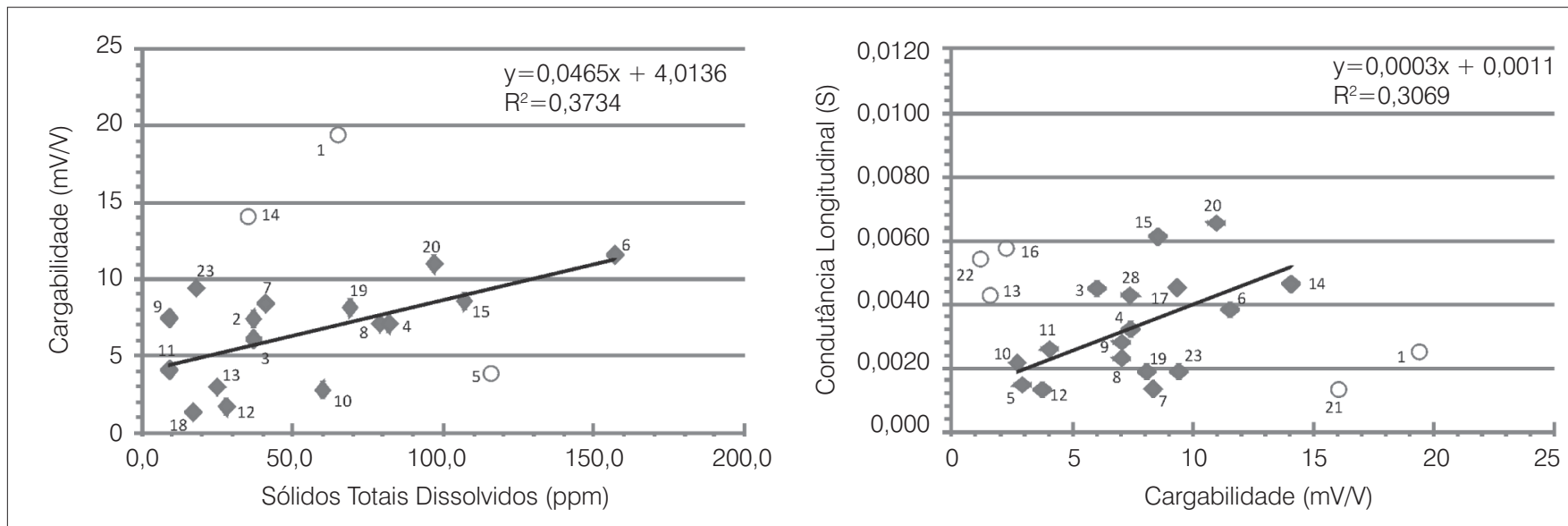

Figura 5 - Transmissividade versus resistividade (esquerda) e transmissividade versus cargabilidade (direita), com linha de tendência, equação da reta, coeficiente de determinação $\mathrm{R}^{2}$ e numeração dos símbolos referentes aos poços apresentados em mapa. 
Já no gráfico cargabilidade versus condutância longitudinal foi realizado um ajuste linear com coeficiente de determinação $\mathrm{R}^{2}=0,3069$. A linha de tendência apresenta relação direta entre parâmetros, com aumento da cargabilidade concomitante ao da condutância longitudinal, embora também numa situação de baixo coeficiente de determinação (Figura 5).

O fenômeno de polarização eletrolítica depende essencialmente da presença de poros com interconectividade e permeabilidade suficiente para permitir o fluxo de fluídos, e que preferencialmente contenham íons dissolvidos. Neste sentido, os resultados revelam que a polarizabilidade do nível aquífero depende diretamente do teor de sais dissolvidos na água, em que maiores teores resultam em valores mais elevados de cargabilidade devido à maior probabilidade de geração de zonas de acúmulo de cargas opostas pelo trânsito de corrente artificial e, consequentemente, de potencial transiente proporcional.

O parâmetro condutância longitudinal, derivado do processamento de sondagens elétricas, tem aplicação em estudos de vulnerabilidade de aquíferos devido à relação de proteção de níveis aquíferos com a argilosidade da camada superior (BRAGA, 2008; HENRIET, 1975; SALEM, 2001; SHEVNIN et al., 2006). Como os dados apresentados neste trabalho são referentes ao nível aquífero, são possíveis discussões acerca da dispersão de contaminantes ao longo da camada aquífera.

A relação de aumento da cargabilidade com o da condutância longitudinal possivelmente reflete o incremento da espessura da camada aquífera, ou seja, do volume de material passível de polarização eletrolítica, conforme sugere também a relação transmissividade versus cargabilidade.

As relações de aumento da transmissividade e da condutância longitudinal com o da cargabilidade claramente indicam associação com porosidade e permeabilidade e, em última análise, como a argilosidade da camada aquífera.

\section{Conclusões}

A análise estatística dos dados demonstrou relação entre condutividade hidráulica medida diretamente em poços rasos com os parâmetros físicos resistividade elétrica e cargabilidade, derivados do processamento, como transmissividade e condutância longitudinal, além do teor de sólidos totais dissolvidos em amostras de água coletados nos poços analisados.

Os parâmetros relacionados nos gráficos de dispersão permitiram o ajuste de linhas de tendência, além de coeficiente de determinação elevados e satisfatórios para o caso das seguintes relações: resistividade versus condutividade hidráulica e cargabilidade versus condutividade hidráulica. Este primeiro cruzamento revela que os condicionantes inerentes à condutividade hidráulica, como aumento da porosidade efetiva, também influenciam de forma direta na queda nos valores de resistividade elétrica para a zona saturada, fato que demonstra sua aplicabilidade em estudos hidrogeológicos e ambientais. Para o segundo caso, é provável que o aumento da porosidade influencie na polarizabilidade do nível aquífero até certo ponto, a partir do qual os valores decrescem com o aumento do fluxo, pois o incremento da porosidade gradativamente limita a quantidade de pontos de estrangulamento de fluído e íons e, consequentemente, de áreas passíveis de polarização eletrolítica.

Os dados relativos à espessura da camada saturada versus resistividade e espessura da camada saturada versus cargabilidade apresentaram ampla dispersão dos dados e inviabilizaram a elaboração de linhas de tendência com coeficientes de correlação razoáveis. Para o segundo caso foi possível estabelecer uma área com predomínio de valores e tendência de variação, que sugere o aumento concomitante de cargabilidade e espessura da camada, algo justificável com base na hipótese do aumento da quantidade de áreas polarizáveis em camadas saturadas cada vez mais espessas.

As relações entre resistividade versus transmissividade e cargabilidade versus transmissividade apresentaram coeficientes de correlação medianos. No primeiro caso houve relação inversa, com queda da resistividade e aumento da transmissividade essencialmente atribuída ao aumento da espessura da camada saturada, ou seja, da quantidade de poros interconectados e permeáveis. Para o segundo caso, estes mesmos fatores colaboram numa relação direta de aumento da cargabilidade, ou seja, incremento relativo da quantidade de zonas localizadas de menor porosidade ou zonas de estrangulamento. A ocorrência de ambas as condições é plausível num contexto de heterogeneidades típicas do ambiente geológico.

No caso das relações de sólidos totais dissolvidos versus cargabilidade e cargabilidade versus condutância longitudinal, as linhas de tendência e equações de reta estão baseadas em coeficientes com baixo grau de relação. Contudo, no primeiro caso há relação direta de aumento concomitante dos parâmetros, o que aponta para o condicionamento da polarizabilidade em meio poroso diretamente associado à disponibilidade iônica neste meio saturado. Já para o segundo, há associação crescente da argilosidade, com a queda na condutância longitudinal e redução da cargabilidade, pois ambientes de baixa permeabilidade dificultam o trânsito de fluídos e íons, algo que limita as condições de polarizabilidade da zona saturada.

Em resumo, os resultados demonstram que a condutividade hidráulica e transmissividade são fatores diretamente associados à variação da resistividade elétrica em camadas saturadas aquíferas. A cargabilidade revelou maior complexidade, pois além de relação com parâmetros comuns à resistividade elétrica, houve também associações com espessura da camada saturada, condutância longitudinal e teor de sólidos totais dissolvidos. 
Desta forma, medidas de cargabilidade do nível aquífero podem servir para estimativas da propagação de contaminantes, estudos de monitoramento e remediação de áreas contaminadas, além de pesquisas de vulnerabilidade de aquíferos, em semelhança ao parâmetro condutância longitudinal. A variabilidade deste parâmetro físico em presença de contaminantes no solo e águas subterrâneas, aliada às alterações relacionadas com processos biogeoquímicos de degradação de contaminantes, também revelam a eficácia de medidas de cargabilidade em diagnósticos ambientais, conforme demonstrado nos trabalhos de Abu-Zeid et al. (2004), Dahlin et al. (2010), Moreira e Braga (2009a, 2009b) e Ustra et al. (2012).

\section{Referências}

ABU-ZEID, N.; BIANCHINI, G.; SANTARATO, G.; VACCARO, C. (2004) Geochemical characterisation and geophysical mapping of landfill leachates: the Marozzo canal case study (NE Italy). Environmental Geology, v. 45, p. 439-47.

BRAGA, A.C.O. (2008) Estimativa da vulnerabilidade natural de aqǘferos: uma contribuição a partir da resistividade e condutância Iongitudinal. Revista Brasileira de Geofísica, v. 26, n. 1, p. 61-8.

BRAGA, A.C.O.; MALAGUTTI FILHO, W.; DOURADO, J.C. (2006) Resistivity (DC) method applied to aquifer protection studies. Revista Brasileira de Geofísica, v. 24, n. 4, p. 573-81.

BRASIL. Ministério do Meio Ambiente. Secretaria de Recursos Hídricos e Ambiente Urbano. (2007) Águas subterrâneas - um recurso a ser conhecido e protegido. Brasília, Ministério do Meio Ambiente. 40 p.

CPRM - Companhia de Pesquisa de Recursos Minerais (2000) Programa Levantamentos Geológicos Básicos do Brasil. Cachoeira do Sul. Folha SH.22-Y-A. Estado do Rio Grande do Sul. Escala 1:250.000. Brasília. CPRM, p. 147.

DAHLIN, T.; ROSQVIST, H.; LEROUX, V. (2010) Resistivity-IP mapping for landfill applications. First Break, v. 28, p. 101-65.

FETTER, C.W. (1994) Applied hydrogeology. 3 ed. New Jersey: PrenticeHall, p. 592

GONÇALVES, V.G.; GIAMPÁ, C.E.Q. (2006) Águas subterrâneas e poços tubulares profundos. São Paulo. Signus Editora, 502 p.

HANSEN, M.A.F.; LIMA, J.P.R.; FRIES, M.; MOREIRA, C.A. (2010) Importância da geofísica no estudo das águas. In: COSTA, A.B. (ORG.). Água e Saúde. 1 ed. UNISC, Porto Alegre, v. 1, p. 200-30.

HENRIET, J.P. (1975) Direct applications of the Dar Zarrouk parameters in ground water surveys. Geophysical Prospecting, n. 24, p. 344-53.

IBGE - Instituto Brasileiro de Geografia e Estatística. Pesquisa nacional de saneamento básico. (2000) Disponível em: <http://www.ibge.gov.br/ home/estatistica/populacao/condicaodevida/pnsb/pnsb.pdf $>$. Acesso em: 10 out. 2011.

IBGE - Instituto Brasileiro de Geografia e Estatística. Mapa exploratório de solos do Rio Grande do Sul. (2002) Disponível em < ftp://geoftp.ibge. gov.br/mapas_tematicos/pedologia/unidades_federacao/rs_pedologia. pdf $>$. Acesso em: 10 out. 2011
KEAREY, P.; BROOKS, M.; HILL, I. (2002) An introduction to geophysical exploration. 3 ed. Oxford: Blackwell, 262 p.

KELLER, G.V. \& FRISCHKNECHT, F.C. (1966) Electrical methods in geophysical prospecting. London: Pergamon Press, $562 \mathrm{p}$.

MELO, J.G.; STEIN, P.; VASCONCELOS, M.B.; SILVA, F.H.R. (2006) Recarga do aqüífero Açu na borda sudoeste da bacia Potiguar Trecho Apodi-Upanema. Revista de Geologia, v. 19, n. 1, p. 61-72.

MOREIRA, C.A.; BRAGA, A.C.O. (2009a) Anomalias de cargabilidade em aterro de resíduos sólidos domiciliares. Revista Brasileira de Geofísica, v. 27, n. 1, p. 55-62

MOREIRA, C.A.; BRAGA, A.C.O. (2009b) Aplicação de métodos geofísicos no monitoramento de área contaminada sob atenuação natural. Revista de Engenharia Sanitária e Ambiental, v. 14, n. 2, p. 257-64.

OKORO, E.I; EGBOKA, B.C.E.; ONWUEMESI, A.G. (2010) Evaluation of the aquifer characteristic of Nanka sands using hydrogeological method in combination with Vertical Electrical Sounding (VES). Journal of Applied Sciences and Environmental Management, v. 14, n. 2, p. 5-9.

PEINADO-GUEVARA, H.J.; RUÍZ, C.R.G.; RODRÍGUEZ, O.D.; BARRIENTOS, J.H.; JIMÉNEZ, S.B.; TORRES, M.A.L.G.; SHEVNIN, V. (2010) Estimación de la conductividad hidráulica y contenido de finos a partir de leyes experimentales que relacionan parámetros hidráulicos y eléctricos. Ra Ximhai, v. 6. n. 3, p. 469-78.

REYNOLDS, J.M. (1997) An introduction to applied and environmental geophysics. Chinchester: John Wiley \& Sons, $796 \mathrm{p}$.

SAINATO, C.M.; LOSINNO, B.N.; GALINDO, G.; LANDINI, A.M.; FAZIO, A.M. (2006) Geofísica aplicada a la evaluación de la vulnerabilidad a la contaminación en zonas rurales de la provincia de Buenos Aires, Argentina. Águas Subterrâneas, v. 20, n. 2, p. 71-82.

SALEM, H.S. (2001) Modelling of lithology and hydraulic conductivity of shallow sediments from resistivity measurements using schlumberger vertical electric soundings. Energy Sources, v. 23, n. 7, p. 599-618.

SHEVNIN, V.; DELGADO-RODRÍGUEZ, O.; MOUSATOV, A.; RYJOV, A (2006) Estimation of hydraulic conductivity on clay content in soil determined from resistivity data. Geofísica Internacional, v. 45, n. 3, p. 195-207.

SOUPIOS, P.M.; KOULI, M.; VALLIANATOS, F.; VAFIDIS, A.; STAVROULAKIS, G. (2007) Estimation of aquifer hydraulic parameters 
from surficial geophysical methods: a case study of Keritis Basin in Chania (Crete - Greece). Journal of Hydrology, v. 338, n. 1-2, p. 122-31.

SOUZA, L.S.B.; VERMA, O.P. (2006) Mapeamento de aqüíferos na cidade de Manaus/AM (zonas norte e leste) através de perfilagem geofísica de poço e sondagem elétrica vertical. Revista de Geologia, v. 19, n. 1, p. 111-27.

SUGUIO, K. (2008) Mudanças ambientais da Terra. São Paulo: Instituto Geológico, 336 p.
SUMNER, J.S. (1976) Principles of induced polarization for geophysical exploration. Amsterdam: Elsevier, 277 p.

TELFORD, W.M.; GELDART, L.P.; SHERIFF, R.E. (2004) Applied geophysics. 2 ed. New York: Cambridge University Press, 774 p.

USTRA, A.T.; ELIS, V.R.; MONDELLI, G.; ZUQUETTE, L.V.; GIACHETI, H.L. (2012) Case study: a 3D resistivity and induced polarization imaging from downstream a waste disposal site in Brazil. Environmental Earth Sciences, v. 66, n. 3, p. 763-72. 